\title{
Interactive comment on "Mountain water cellars: a chemical characterization and quantification of the hydrological processes and contributions from snow, glaciers and groundwater to the Upper Mendoza River basin ( $\left.\sim 32^{\circ} \mathrm{S}\right)$, Argentina” by Sebastián A. Crespo et al.
}

Anonymous Referee \#2

Received and published: 3 July 2018

General comments

This study aims to investigate the contribution of snow, glacier and groundwater to streamflow runoff generation in data sparse region Andes region. The analysis is based on meteorological and hydrological (streamflow and isotope) measurements at four stations in the period 2013/2014. The authors conclude that the contribution from glaciers increases towards summer season. 
Overall the topic of understanding of different pathways and contribution of snow melt and groundwater processes on streamflow generation is very interesting and within the scope of the journal. This is particularly interesting in the Andes, which is the region with distinct seasonality of runoff generation processes compared to many other places in the world. However the manuscript is, unfortunately, not ready for publication in its current form. The main reasons for such critical conclusion are:

Interactive

1) The significant lack of clarity of presentation, particularly the English. There are many parts which are not clearly formulated so a proof-reading by native speaker is strongly recommended.

2) The context for the analysis is not clear. Is the aim to analyse and compare the runoff generation processes during the extra drought event (2010-2015) only? If so, then I missed some more information on how this period differs/compares with a normal situation. Is this drought defined in terms of precipitation deficit only? Or also in terms of streamflow? What are the differences to other studies on such topic? Why it is interesting/important to look at it in the Andes?

3) The objectives needs to be reformulated in order to more clearly show the scientific novelty and significance compared to existing studies. The research hypotheses are in its current form rather obvious. E.g. Which environmental variables control the initial thawing. Is it not the physics and energy balance which is controlling that? I would suggest to bring forward more the context of comparative hydrology to justify the significance and contribution of the paper.

4) The data description is not rigorous. I missed more information about the temporal resolution of the data and time period. Is only one season available? Is it enough to draw some more general interpretations? Are there some other/longer data sets available?

5) I missed some more process based interpretation of the results. The linear regression between streamflow and some climatic data seems to me not enough to justify

Printer-friendly version

Discussion paper 
the interpretations about the contributions of individual variables. Why not to use a hydrological model for the analysis?

6) The discussion of the results can be improved. What has been learned compared to other existing studies (i.e. related to the assessment of drought controls in other regions/climates, or related to normal situation in similar regions?) In its current form it reads more as a summary.

Interactive

comment

Interactive comment on Hydrol. Earth Syst. Sci. Discuss., https://doi.org/10.5194/hess-2018212, 2018. 